\title{
Investigating Maternal Mortality at Regina Pacis Hospital Mutengene and the Government Health Centre Mutengene, South West Region, Cameroon
}

\author{
Ngwa Fabrice Ambe ${ }^{1,2^{*}}$, Tanyi Pride Bobga1,2,3, Mohamed Isah", Ateh Stanislas Ketum ${ }^{5}$, \\ Carlson Babila Sama ${ }^{6}$, Acha Anwi Therese ${ }^{7}$, Ngouateu Chrysal Beuadou, \\ Ebanja Silva Elonge Gabriel'5, Thierry Pechap Ayafor ${ }^{9}$
}

\footnotetext{
${ }^{1}$ Department of Medical Laboratory Sciences, Faculty Health Sciences, University of Buea, Buea, Cameroon

${ }^{2}$ Department of Microbiology and Parasitology, Faculty of Science, University of Buea, Buea, Cameroon

${ }^{3}$ Saint Louis Institute of Medical Sciences, Douala,Cameroon

${ }^{4}$ Department of Public Health and Hygiene, Faculty Health Sciences, University of Buea, Buea, Cameroon

${ }^{5}$ Department of Medicine, Faculty Health Sciences, University of Buea, Buea, Cameroon

${ }^{6}$ Western Sussex NHS Foundation Trust and School of Population Health Sciences, Department of Global Health, University

College London, London, UK

${ }^{7}$ Department of International Public Health, Liverpool School of Tropical Medicine, Liverpool, UK

${ }^{8}$ Tuberculosis Reference Laboratory, Bamenda, Cameroon

${ }^{9}$ University of Alabama, Birmingham, USA

Email: ^ngwafabrice12@gmail.com, bobgatanyi@yahoo.com,mohamedisahmi@gmail.com, atehstanilask@gmail.com, elongaterre@gmail.com, anwijunior@gmail.com,sama.carlson@yahoo.com,chrysald45@gmail.com,pechap@uab.edu
}

How to cite this paper: Ambe, N.F., Bobga, T.P., Isah, M., Ketum, A.S., Sama, C.B., Therese, A.A., Beuadou, N.C., Gabriel, E.S.E. and Ayafor, T.P. (2020) Investigating Maternal Mortality at Regina Pacis Hospital Mutengene and the Government Health Centre Mutengene, South West Region, Cameroon. Journal of Biosciences and Medicines, 8, 163-176.

https://doi.org/10.4236/jbm.2020.85016

Received: January 31,2020

Accepted: May 17, 2020

Published: May 20, 2020

\begin{abstract}
Background: One target under sustainable Development Goal 3 is to reduce the global maternal mortality ratio to less than 70 per 100,000 births, with no country having a maternal mortality rate of more than twice the global average. So there is a need to identify ways to reduce maternal mortality which is a top priority in development of the management of pregnant women and invention of equipment in procedures (caesarian section) to provide a maternal health and increase life survival. Objective: This study aimed to investigate the prevalence and causes of maternal mortality at Regina Pacis Hospital and Government Health Center Mutengene. Method: This study was a retrospective study, where Data from 2007 to 2017 were collected from the hospital files using a checklist, descriptive and inferential statistics were used to analyse the data. Conclusion: From the finding, maternal mortality is at a pace of increase in the Regina Pacis Hospital and Government Health Centre Mutengene and
\end{abstract}


Copyright () 2020 by author(s) and Scientific Research Publishing Inc. This work is licensed under the Creative Commons Attribution International License (CC BY 4.0).

http://creativecommons.org/licenses/by/4.0/ these health facilitiesmay fail to achieve the target of SDG3 by the end of 2030 . Since, the overall prevalence of maternal mortality at both study sites was 240 per 100,000 live births at Regina Pacis Hospital and Government Health Center Mutengene from 2007 to 2017, increase education of women of reproductive age on pregnancy care and training of hospital staff in obstetric management and health records documentation.

\section{Keywords}

Maternal Mortality, South West Region, Cameroon, Pregnancy and Hemorrhage

\section{Background}

According to the World Health Organization (2014) [1], maternal death is defined as the death of a woman while pregnant or within 42 days of termination of the pregnancy, from any cause related to or aggravated by the pregnancy or its management but not from accidental or incidental causes. Generally, there is a distinction between direct factors that causes maternal mortality and indirect factors. Direct factors include complication resulting from pregnancy, delivery, management of the two (mother and baby). While indirect factors are malaria, anaemia, and hypertension all of which may complicate pregnancy [2].

Worldwide, maternal mortality is unacceptably high; approximately 800 women die every day from preventable causes related to pregnancy and delivery. In 2009, WHO (World Health Organization) established a set of criteria for severe acute maternal morbidity and maternal near miss in order to standardized data and calculate indicators for comparing different settings and identify cases of interest. Furthermore, maternal mortality ratio in Brazil is about 60.1/100,000 lives birth (LB) and a total of 1,719 deaths were occurred in 2010. Also in Brazil, the main causes of maternal deaths in 2014 were hypertension (21.1\%), hemorrhage (11.9\%), complications of labor (8.6\%) and HIV and infectious diseases (5\%) [3].

However, between 1990 and 2013, the global maternal mortality ratio (that is, the number of maternal death per 100,000 live births) declined by only 2.65 per year [4], this is far from the annual decline of $5.5 \%$ required to achieve Millennium Development Goal 5 (MDG 5) [4].

Improving maternal mortality by providing evidence based clinical and programmatic guidance, setting global standard, and providing technical support to member states [5]. A global strategy for women's and children's health, aim at saving the lives of more than 16 million women and children over the next four years was launched during the United Nation MDGs summit in September 2010 by the UN Secretary-General Banki-Moon [6]. Also in Cameroon during the period of 2007 to 2011, Cameroon had reported maternal mortality ratio of 670 deaths per 100,000 lives birth [7]. Based on this data, Cameroon did not achieve the target in 2015 (590 deaths per 100,000 live births) [5]. 
During the United Nations General Assembly 2015, in New York, UN Secretary-General Ban Ki-moon launched the Global Strategy for Women's, Children's and Adolescents' Health, between 2016-2030 [6]. Seeing that it is possible to accelerate the decline, countries have now united behind a new target to reduce maternal mortality even further. One target under Sustainable Development Goal 3 is to reduce the global maternal mortality ratio to less than 70 per 100,000 births, with no country having a maternal mortality rate of more than twice the global average. The Strategy is a road map for the post-2015 agenda as described by the Sustainable Development Goals and seeks to end all preventable deaths of women, children and adolescents and create an environment in which these groups not only survive, but thrive, and see their environments, health and wellbeing transformed. So there is a need for further investment in medical staff training, construction of more medical district hospital and evidence-based management and prevention standards.

Maternal health is improving and maintaining wellbeing and development of mothers before, during and after delivery. In Cameroon, the prevalence of maternal mortality is still challenging in health services. According to the statistics from the United Nations, World Bank in 2010-2015 [7], Cameroon was not among the 9 countries that achieve the MDG5 although the government development vision under health policy 1 of its strategy is reducing burden of maternal mortality and increasing life through the improvement of health services to all people [5]. So if more effective measures are not taken, the prevalence of maternal mortality will continue to worsen the burden in health systems and economic growth of the country [8] and Cameroon might not meet the Sustainable Development Goal 3 to reduce the global maternal mortality ratio to less than 70 per 100,000 births, with no country having a maternal mortality rate of more than twice the global average. So there is a need to identify ways to reduce maternal mortality which is a top priority in development of the management of pregnant women and invention of equipment in procedures (Caesarian section) to provide a maternal health and increase life survival [5]. Many mothers also forget the fact that, they must not only be knowledgeable through clinic sections, but to seek information from different sources such as the media, books and the internet about safe motherhood. To assess the achievement of MDG 5, planners as well as policy makers did estimated number of maternal mortality, without the substantial information from MDG 5, with these results the target for SDG 3 might not be achieved. Thus, it prompt us to carry out a research on maternal mortality to continue the trend if the SDG 3 goal will be met by 2030 .

\section{Research Methodology}

\subsection{Research Design}

This study was a retrospective study, where supposed files of women of reproductive age that consulted at the Regina Pacis Hospital and Government Health Center Mutengene were utilised for the study. At enrolment, checklist was used 
to collect data from past records of women of reproductive age who consult at the Regina Pacis Hospital and Government Health Centre Mutengene from 2007 to 2017. The variables collected from the data were age, risk factors (anaemia, malaria, hemorrhage, prolongs labour, sepsis, HIV/AIDS and abortion) and other factors.

\subsection{Study Area}

This study was carryout in Mutengene, on the prevalence of maternal mortality at the Regina Pacis Hospital and Government Health Center Mutengene. Mutengene is located in between Buea, Limbe and Tiko (Douala) in Fako Division, South West region, Cameroon. Mutengene has a population of 43,048 habitants as part of the municipality of Tiko with a surface area of $484 \mathrm{~km}$ squared and under the Tiko health district. The inhabitants are mainly traders, farmers and fishermen due to the presence of rich soil, rivers and streams and business atmosphere. It's also has a coastal equatorial climate with two seasons: long rainy and short dry seasons.

\subsection{Study Population}

The target population were women of reproductive age who consulted at Regina Pacis Hospital Mutengene and Government Health Centre Mutengene from 2007 to 2017. A total of 8013 hospital records of pregnant women in the study site who registered for delivery from 2007 to 2017 were reviewed. 5124 participants were from Regina Pacis Hospital Mutengene and 2889 participants were from Government Health Centre Mutengene.

\subsection{Sampling Technique}

We used convenient sampling to study the files, from 2007 to 2017.

\subsection{Sample Size}

This study included all files of pregnant women from the selected areas: Regina Pacis Hospital Mutengene and Government Health Centre Mutengene from 2007 to 2017 to give a reasonable conclusion over the 10 -year period.

\subsection{Selection Criteria}

\subsubsection{Inclusion Criteria}

All women of reproductive age who delivered in the maternity at the Regina Pacis Hospital Mutengene and Government Health Centre Mutengene were included in this study.

\subsubsection{Exclusion Criteria}

All women who were not pregnant and women whose files had incomplete valuable information as stipulated by the checklist were excluded from the study.

\subsection{Data Collection}

The instrument we used was a checklist to collect data from past records of women 
of reproductive age who consult at the Regina Pacis Hospital and Government Health Centre Mutengene from 2007 to 2017. The variables collected from the data were age, risk factors (anaemia, malaria, hemorrhage, prolong labour, sepsis, HIV/AIDS and abortion) and other factors.

\subsection{Validation of Instrument}

A checklist was design according to the study objectives presented to the supervisor for scrutiny. After which a pilot study was used in a study area to get challenges in collecting data.

Necessary corrections were then effected together with the supervisor thereby respecting face and content validity.

\subsection{Ethical Consideration}

Names of patients were notmentioned; just record numbers were used in order to maintain confidentiality. The information we collected was used strictly for academic purposes. A letter of authorization was collected from SMU, Delegation of Public Health and from the administration of two Hospitals. An ethical clearance for this research was obtained from the Institutional Review Board (IRB) of the Faculty of Health Sciences (FHS) of the University of Buea.

\subsection{Data Analysis}

Data was collected with the use of a checklist which was later keyed into a Statistical Package for Social Sciences (SPSS) version 20 and Microsoft Excel 2013. Findings were presented in pie charts and frequency distribution tables.

\section{Results}

\subsection{Socio-Demographic Data}

\subsubsection{Distribution of Participants According to Number of Files Worked Upon}

A total of 8013 hospital records on the number of mothers in the study site who registered for delivery from 2007 to 2017 were reviewed. Majority of the participants $(64 \%, \mathrm{n}=5124)$ were from Regina Pacis Hospital Mutengene while a minority $(36 \%, 2889)$ were from Government Health Centre Mutengene (Figure 1).

\subsubsection{Number of Cases with Respondents Less than 18 and Greater than 35 Years}

In this study, majority of the cases less than 18 years of age were from Regina Pacis Hospital Mutengene $(53.3 \%, \mathrm{n}=122)$, with a minority from the Government Health Centre Mutengene $(46.7 \%, \mathrm{n}=107)$. Out of the 276 cases greater than 35 years recorded, 176 (63.8\%) were from Regina Pacis hospital and 100 (36.2\%) were from Government Health Centre Mutengene as shown below (Table 1).

\subsubsection{Presentation of Respondents According to Parity}

Of 1537 Prime Cases recorded in this study, majority 1049 (68\%) were from Re- 
gina Pacis Hospital Mutengene and minority 488 (32\%) were from Government Health Centre Mutengene. Of 1114 Multipara Cases, recorded the majority in this study, 647 (58\%) were from Regina Pacis Hospital Mutengene and minority 467 (42\%) were from Government Health Centre Mutengene (Table 2).

\subsection{The Prevalence of Maternal Mortality at the Study Area}

Based on the table below on babies, the total value 3696 were babies that lived and 105 were babies that died in Regina Pacis Mutengene while in Government Health Centre Mutengene, 2019 babies lived and 42 babies died (Table 3).

In terms of year, 2012 presented with the highest value $(n=490)$ of lived birth and 2013 presented the highest value $(n=17)$ of babies who died. While the Government Health Centre Mutengene, 2016 presented the highest value of babies that lived $(n=623)$ and that died $(n=18)$. Furthermore, based on mothers,

Table 1. Results showing the number of cases with respondents less than 18 and greater than 35 years.

\begin{tabular}{ccccc}
\hline & & \multicolumn{3}{c}{ Frequency (Percentage) } \\
\cline { 3 - 5 } SN & Study area & $\begin{array}{c}\text { Cases less than } \\
18 \text { years }\end{array}$ & $\begin{array}{c}\text { Case between } \\
19-34 \text { years }\end{array}$ & $\begin{array}{c}\text { Cases greater } \\
\text { than 35years }\end{array}$ \\
\hline 1 & Regina Pacis Hospital & $122(53.3 \%)$ & $102(54.2 \%)$ & $176(63.8 \%)$ \\
2 & Gov't Health Centre Mutengene & $107(46.7 \%)$ & $86(45.6 \%)$ & $100(36.2 \%)$ \\
Total & 229 & 188 & 276
\end{tabular}

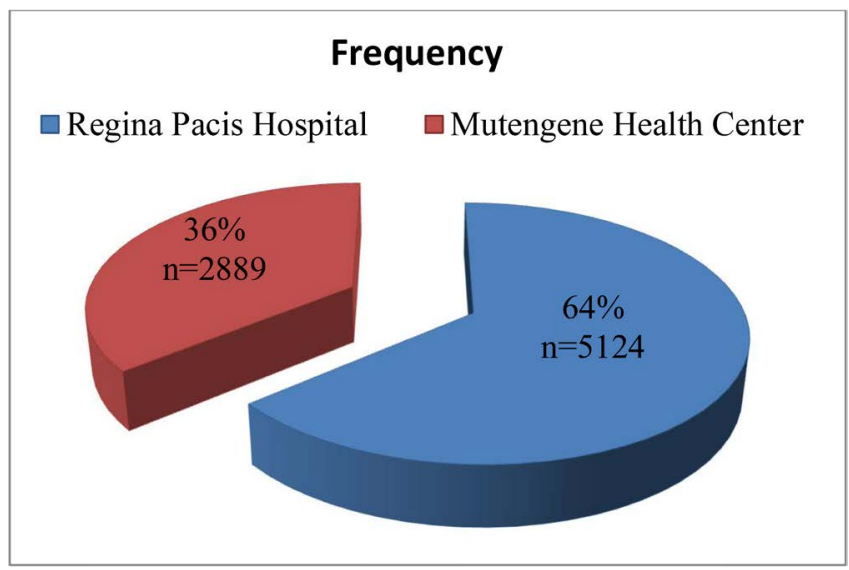

Figure 1. Pie chart showing the distribution of participants according to number of files worked upon.

Table 2. Results showing respondents presentation according to parity.

\begin{tabular}{ccccc}
\hline \multirow{2}{*}{ SN } & Parameter & \multicolumn{2}{c}{ Frequency (percentage) } & \multirow{2}{*}{ Total } \\
\cline { 3 - 4 } & & Regina Pacis Hosp. M & Gov’t Health Centre M & \\
\hline 1 & Cases with Prime & $1049(68 \%)$ & $488(32 \%)$ & 1537 \\
3 & Cases with Multipara & $647(58 \%)$ & $467(42 \%)$ & 1114 \\
\hline
\end{tabular}


Table 3. Results showing the prevalence of maternal mortality and maternal mortality rate at the study area.

\begin{tabular}{|c|c|c|c|c|c|c|c|c|c|c|c|c|}
\hline Year & & 2007 & 2008 & 2009 & 2010 & 2011 & 2012 & 2013 & 2014 & 2015 & 2016 & 2017 \\
\hline \multirow{5}{*}{$\begin{array}{l}\text { Regina Pacis } \\
\text { Mutengene }\end{array}$} & Babies alive & 140 & 202 & 299 & 301 & 198 & 490 & 433 & 449 & 359 & 449 & 366 \\
\hline & Babies death & 1 & 8 & 5 & 8 & 3 & 15 & 17 & 15 & 9 & 8 & 16 \\
\hline & Mothers alive & 142 & 210 & 306 & 309 & 201 & 498 & 449 & 457 & 362 & 446 & 400 \\
\hline & Maternal death & 0 & 0 & 2 & 0 & 0 & 1 & 2 & 5 & 2 & 0 & 1 \\
\hline & Maternal Mortality Rate & 0 & 0 & 653.6 & 0 & 0 & 445.4 & 1094.0 & 552.5 & 250.0 & 0 & 2127.6 \\
\hline \multirow{5}{*}{$\begin{array}{c}\text { Mutengene } \\
\text { Health Center }\end{array}$} & Babiesalive & - & - & - & - & - & - & - & 503 & 353 & 623 & 540 \\
\hline & Babies death & - & - & - & - & - & - & - & 4 & 3 & 18 & 12 \\
\hline & Mothersalive & - & - & - & - & - & - & - & 504 & 357 & 640 & 547 \\
\hline & Maternal death & - & - & - & - & - & - & - & 0 & 0 & 1 & 0 \\
\hline & Maternal Mortality Rate & - & - & - & - & - & - & - & 0 & 0 & 156.3 & 0 \\
\hline
\end{tabular}

the result shows, the total number of 5124 mothers that lived and 13 were mothers that died in Regina Pacis Mutengene while the Government Health Centre Mutengene, had a total number of 2889 mothers that lived and 1 mother that died (Table 3).

In terms of year 2012 presented with the highest value $(n=698)$ of lived birth mothers and 2013 presented the highest value $(n=5)$ of mothers who died in Regina Pacis Mutengene. While the Government Health Centre Mutengene, in 2016 presented the highest value of babies that lived $(n=640)$ and that died $(n=1)$

(Table 3).

\subsection{The Maternal Mortality Rate at the Study Area}

\subsubsection{The Maternal Mortality Rate at Regina Pacis}

The prevalence of maternal death at Regina Pacis Hospital was determined to be 255 per 100,000 live births from 2007 to 2017, with a total live birth of 5111 and 13 deaths out of 5124 mothers in the study. There was a higher prevalence of infant mortality of 28,410 per 100.000 live births within the same specified period of study (Table 3).

\subsubsection{The Maternal Mortality Rate at the Government Health Centre Mutengene}

A total of 2888 mothers successfully gave birth from 2014-2017 in the Government Health Centre Mutengene and 1 died out of 2889 mothers in the study. A value of 35 per 100,000 live births was recorded, with a corresponding infant death of 20810 per 100,000 live births. Thus, the overall prevalence of maternal mortality and infant mortality at both study sites were 240 per 100,000 live births and 250 per 100,000 live births respectively (Table 3).

\subsubsection{Rate of Maternal Mortality between Regina Pacis Hospital and Government Health Centre Mutengene per Year}

2014 presented the highest MMR per year with value $14,410.17$ per 100,000 live 
birth at the Regina Pacis Hospital Mutengene. Whereas, 2016 presented the highest MMR per year with value 1587.302 per 100,000 live birth at the Mutengene Health Centre (Figure 2).

\subsection{Most Prominent Cause of Maternal Mortality at Regina Pacis Hospital and Government Health Centre Mutengene.}

\subsubsection{Frequency Distribution of Risks Factors of Maternal Mortality at the Study Area}

At the time of admission of the 3458 pregnant women at the Regina Pacis Hospital Mutengene, 1988 (57.5\%) cases of malaria, 853 (24.7\%) cases of Sepsis, and $86(2.5 \%)$ cases of other conditions (Anaemia) were reported. At the time of admission of the 1233 pregnant women at the Government Health Centre Mutengene, $702(56.9 \%)$ cases of Malaria, 247 (20.1\%) cases of Sepsis and 17 (1.4\%) cases of other conditions (Anaemia) were recorded (Table 4).

\subsubsection{Investigating the Causes and Number of Deaths at the Study Area}

Haemorrhage was the most related factor of death associated with $1(100 \%)$ death at the Government Health Centre Mutengene. Also, It was associated with 3 (46\%) of the 13 recorded maternal mortality. prolonged labour and Malaria associated with $2(15 \%)$ respectively of the 13 recorded death while Anaemia, Abortion, Sepsis and HIV/AIDS were associated with 1(6\%) deaths each at the Regina Pacis Mutengene (Table 5).

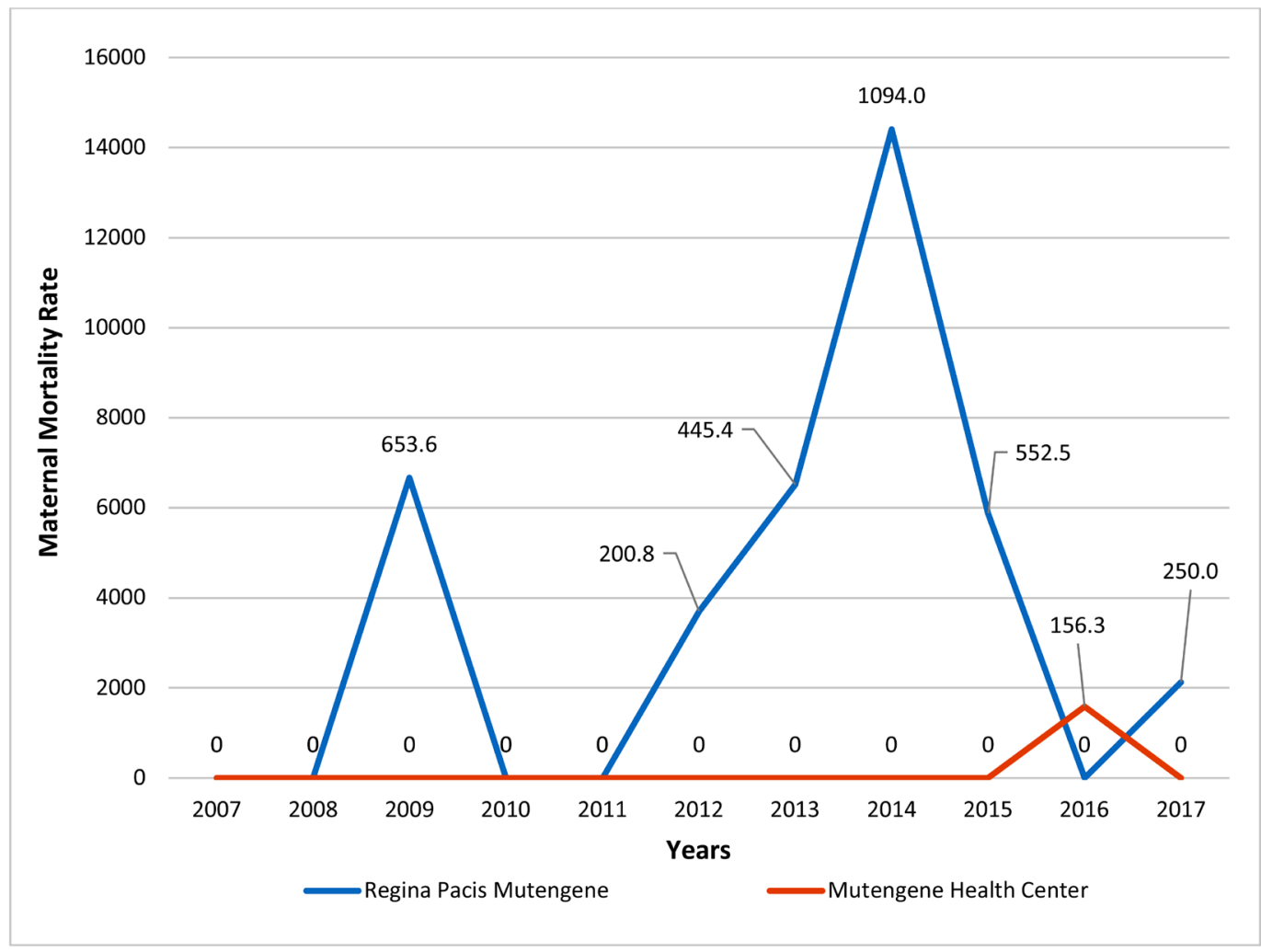

Figure 2. Graph showing the rate of maternal mortality between Regina Pacis Hospital and Government Health Centre Mutengene per year. 
Table 4. Results showing the causes/risks factors of maternal mortality at the study area.

\begin{tabular}{ccccc}
\hline \multirow{2}{*}{ SN } & \multirow{2}{*}{$\begin{array}{c}\text { Risks Factors of } \\
\text { Maternal mortality }\end{array}$} & \multicolumn{2}{c}{ Frequencies (percentage) } & \multirow{2}{*}{ Total } \\
\cline { 3 - 4 } & Regina Pacis Hospital M. & Gov't Health Centre M. & \\
\hline 1. & Abortion & $87(2.5 \%)$ & $23(1.9 \%)$ & 110 \\
2. & Haemorrhage & $67(1.9 \%)$ & $51(4.1 \%)$ & 118 \\
3. & Hypertension & $104(3.0 \%)$ & $83(6.7 \%)$ & 187 \\
4. & Malaria & $1988(57.5 \%)$ & $702(56.9 \%)$ & 2690 \\
5. & Anaemia & $86(2.5 \%)$ & $17(1.4 \%)$ & 103 \\
6. & Sepsis & $853(24.7 \%)$ & $247(20.1 \%)$ & 1100 \\
7. & HIV/AIDS & $273(7.9)$ & $110(8.9 \%)$ & 383 \\
& Total & $3458(100 \%)$ & $1233(100 \%)$ & 4691 \\
\hline
\end{tabular}

Table 5. Frequency distribution on causes of death at the study area.

\begin{tabular}{ccccc}
\hline \multirow{2}{*}{ SN } & \multirow{2}{*}{$\begin{array}{c}\text { Cause of Maternal } \\
\text { Mortality }\end{array}$} & \multicolumn{2}{c}{ Frequencies (percentage) } & \multirow{2}{*}{ Total } \\
\cline { 3 - 4 } & Regina Pacis Hospital M. & Gov’t Health Centre M. & \\
\hline 1. & Haemorrhage & $3(46 \%)$ & $1(100 \%)$ & 3 \\
2. & Prolonged Labour & $2(15 \%)$ & $0(0 \%)$ & 2 \\
3. & Malaria & $2(15 \%)$ & $0(0 \%)$ & 2 \\
4. & Anaemia & $1(6 \%)$ & $0(0 \%)$ & 1 \\
5. & Abortion & $1(6 \%)$ & $0(0 \%)$ & 1 \\
6. & Sepsis & $1(6 \%)$ & $0(0 \%)$ & 1 \\
7. & HIV/AIDS & $1(6 \%)$ & $0(0 \%)$ & 1 \\
& Total & $13(100 \%)$ & $1(100 \%)$ & 14 \\
\hline
\end{tabular}

\section{Discussion}

In this study, it was noticed that out of 8013 pregnant women files from the year 2007 to 2017, most of the pregnant women $(\mathrm{n}=5124,64 \%)$ registered at Regina Pacis Hospital Mutengene while the least $(\mathrm{n}=2889,36 \%)$ registered at the Government Health Centre Mutengene. This is due to the fact that most of the records at the Government Health Centre Mutengene from 2014 to 2017 were they only record of pregnant women available. This means some of the record got bad, missing and had little or no information about the pregnant women. Regina Pacis Mutengene Hospital indicates that pregnant women of less than 18 years $(\mathrm{n}=122,53 \%)$ and greater than 35 years $(\mathrm{n}=176,63.8 \%)$ are the majority that consulted the hospital. This is in accordance with Lancet Global Health report that pregnant adolescent and secondly women older than 35 years are at risk due to biological immaturity and social conditions which are in the prime biological [9]. Delaying 100,000 adolescent pregnancies until age 20 - 24 years would prevent 70 maternal death, whereas more than 1000 deaths would be prevented if 100,000 pregnancies currently in women age 40 years or older occurred when 
the same women were in their early 20 s. Of 1537 Prime Cases recorded the majority in this study, 1049 (68\%) were from Regina Pacis Hospital Mutengene and minority 488 (32\%) were from Government Health Centre Mutengene. Of 1114 Multipara Cases, recorded the majority in this study, 647 (58\%) were from Regina Pacis Hospital Mutengene and minority 467 (42\%) were from Government Health Centre Mutengene. This is in contrast with the research carryout in Nigeria by lorretta F Ntoimo et al. [10] were minority (31\%) were Prime (nulliparous) and Majority (37\%) were multiparous. Parity is positively associated with outcomes such as anaemia, low maternal weight gain and low-birth weight.

According, to the result from Regina Pacis Hospital Mutengene 3800 pregnant women lived and 13 pregnant women died giving a MMR of 342 maternal deaths per 100,000 live births. Whereas at Government Health Centre Mutengene, 2048 pregnant women lived and 1 pregnant woman died giving a MMR of 49 deaths per 100,000 live births. For the individual health institution the MMR is high at the Regina Pacis Hospital Mutengene and Low at the Government Health Centre Mutengene. Conforming the hypothesis that, there is a difference between the prevalence of Maternal Mortality between the two hospitals. Comparing this result with that of Cameroon national MMR (596 deaths per 100,000 live births) in 2015 the MMR has reduce by Cameroon national demographic and health survey [11]. Also combing the result of the two hospitals as they are serving one population around the same area beside the Mutengene market the MMR is 240 deaths per 100,000 live births. Which is very high according to WHO global target for 2030 of less than 70 deaths per 100,000 live births and higher than the supplementary goal that no country should have a MMR greater than 140. In addition to the relatively inferences to the number of maternal death, the result is limited to women who were treated in facilities, which might under represent mortality due to deaths that occurred outside the health care facility. The observations highlight the continued challenges of maternal mortality and need to improve the health and some medical care of pregnant women in some areas. This result should sparked national outrage to focus on addressing health related issues and socio-economic inequalities in areas such as education, poverty, gender equality, child mortality, maternal health and infectious diseases. If this is not put in place, will be an unjust human right violation and Cameroon will not be able to meet the SDG ending maternal death by 2030. Thus requiring us to redouble our efforts said by, Senior Director of Health, Nutrition and population at World Bank Group "Dr. Tim Evans”.

Among the two hospitals, malaria was the major leading risk factor on admission and places the pregnant women at risk. Regina Pacis Hospital Mutengene had 1988 (57.5\%) pregnant women with Malaria While Government Health Mutengene had 702 (56.9\%) pregnant women with Malaria.This is in accordance with research carryout in Mozambique were Malaria is the leading risk factor in pregnant women in the health system, with $44 \%$ out-patient visits due to Malaria as carryout by Singh K et al. 2014 [12]. This could be due to the fact that Malaria 
is a highly infectious disease; influence by Mosquito breeding such as: temperature, humidity and rainfall which affect malaria incidence. Thus puts pregnant women at highest risk for morbidity and mortality. Whereas, fewer women pregnant came to Regina Pacis Hospital Mutengene with Haemorrhage ( $n=67,1.9 \%$ ). And abortion $(n=23,1.9 \%)$ in the Government Health Centre Mutengene.

Furthermore, Haemorrhage was shown to be the Major cause of maternal Mortality. It associated with 3 out of 13 recorded death at Regina Pacis Mutengene and the only cause of Maternal Mortality at the Government Health Centre Mutengene of $1(100 \%)$ maternal death. Haemorrhage has also been identified as a leading cause of Maternal Mortality in Cameroon [13] and Nigeria [14]. Haemorrhage may be cause by failure of Uterine Muscle to contract, compromised immune system, poor bleeding factor and presence of fibroids or placenta fragment. Also, could come from lack of proper and standard medical intervention and late arrival of client at the hospital. Also, prolonged labour and Malaria were found to be other leading cause of Maternal Mortality in the study sites. Mutihir et al. [14] and Njotang et al., [13] have shown similar findings in Nigeria and Cameroon.

2014 had the highest MMR of 14,410.1 deaths per 100,000 live births in Regina Pacis Hospital Mutengene while Government Health Centre Mutengene had the lowest MMR of 1587.302 deaths per 100,000 live births in 2016. These value is higher than the value carryout in 2015 (590 deaths per 100,000 live birth) in Cameroon by WHO [1]. And that of the Sustainable Development Goal declared in September 2015 by WHO that is, 70 deaths per 100,000 live birth. By national development and survey in Cameroon a facility based maternal death reviews was put in place in 2010 to train every hospital in 150 districts. These results point out to gaps like no intervention to reduce financial barrier to obstetric care which cost is a major factor contributing to delayed care seeking, and poor infrastructure, need for strong leadership, dedicated coordinators and regular team coaching could help meet up the Sustainable Development Goal by 2030.

\section{Conclusion}

The study sought to investigate the prevalence and causes of maternal mortality at Regina Pacis Hospital Mutengene and Government Health Centre Mutengene in Tiko subdivision. The study found that, the prevalence of maternal death at Regina Pacis Hospital was determined to be 342 per 100,000 live births from 2007 to 2017, with a total live birth of 3800 and 13 deaths. There was a higher prevalence of infant mortality of 2841 per 1000 live birth within the same specified period of study. A total of 2048 mothers successfully gave birth from 2014-2017 in the Government Health Centre Mutengene. A value of 49 per 100,000 live births was recorded, with a corresponding infant death of 2081 per 1.000 live births. Furthermore, the study found that Haemorrhage was the major cause of maternal mortality. It associated with 3 out of 13 recorded death at Regina Pacis Mutengene and the only cause of Maternal Mortality at the Government Health 
Centre Mutengene of $1(100 \%)$ death. Prolonged labour and Malaria associated with $2(15 \%)$ respectively of the 13 recorded death while Anaemia, Abortion, Sepsis and HIV/AIDS were associated with 1 (6\%) deaths each at Regina Pacis Mutengene. Generally, result from the finding is at a pace of increased death in the Regina Pacis Hospital Mutengene and Government Health Centre Mutengene and is not sufficient to meet the SDG3 target by the end of 2030. Since, the overall prevalence of maternal mortality and infant mortality at both study sites were 240 per 100,000 live births and 250 per 100,000 live births respectively in Regina Pacis Hospital Mutengene and Government Health Centre Mutengene from the year 2007 to 2017.

\section{Recommendations}

Pregnant women should be educated and encouraged by nurses of the Regina Pacis Hospital Mutengene and Government Health Centre Mutengene to attained antenatal clinics aiding identification of complications like compromised immune system as early as possible.

Pregnant women should be sensitized by nurses at Regina Pacis Hospital Mutengene and Government Health Centre Mutengene to seek more information from different sources such as the media, books and the internet about safe motherhood, and causes of maternal ill health and death to help them participate in optimising their health and improve birth outcomes.

Nurses at Regina Pacis Hospital Mutengene and Government Health Centre Mutengene need to improve on their filing and clerking system and try to upgrade their professional standard to better manage pregnant women especially during delivery.

The ministry of public health should train and provide more staff competent to manage pregnant women.

\section{Limitation of the Study}

This study need to be carryout in different regions of the country, to but understand the risk factors of maternal mortality.

\section{Ethics Approval and Consent to Participate}

A letter of authorization was collected from Saint Monica University. This was used to obtained Administrative authorization from the Regional Delegation of Public Health, Regina Pacis Hospital and Government Health Center Mutengene in South West Region. An ethical clearance for this research was obtained from the Institutional Review Board (IRB) of the Faculty of Health Sciences (FHS), University of Buea, Cameroon.

\section{Availability of Data and Materials}

The datasets used and/or analysed during the current study available from the corresponding author on reasonable request. 


\section{Acknowledgements}

We are grateful to all who participated in this research.

\section{Authors' Contributions}

NFA, TPB, ASK, MAA, AAT, and ABA conceived and designed the study: NFA and MI implement the study: ASK and TP supervised the study: NFA and MI conducted data analysis: ASK, NFA, TPB, ABA, AAT, EEN, and MAA interpreted study results: TPB and NFA wrote the first draft of the manuscript, MI, NFA, NMC and EEN reviewed and corrected the manuscript. All authors approved the final copy.

\section{Conflicts of Interest}

The authors declare no conflicts of interest regarding the publication of this paper.

\section{References}

[1] WHO (2015) Maternal Mortality: Fact Sheet No. 348. World Health Organization, Geneva.

[2] Azuh, D.E., Azuh, A.E., Iweala, E.J., Adeloye, D., Akanbi, M. and Mordi, R.C. (2017) Factors Influencing Maternal Mortality among Rural Communities in Southwestern Nigeria. International Journal of Women's Health, 9, 179-188. https://doi.org/10.2147/IJWH.S120184

[3] UNICEF, WHO, World Bank, United Nations Population Division (2013) The Inter-Agency Group for Child Mortality Estimation (UN IGME) Levels and Trends in Child Mortality. Report 2013. UNICEF, New York.

[4] WHO (2014) World Health Statistics 2014. World Health Organization, Geneva.

[5] WHO (2010) The Commonest Causes of Anaemia Are Poor Nutrition, Iron, and Other Micronutrient Deficiencies, Which Are in Addition to Malaria, Hookworm, and Schistosomiasis. World Health Organisation, Geneva.

[6] UNICEF, UNFPA, World Bank Group (2012) Trends in Maternal Mortality: 1990 to 2010. WHO, UNICEF.

[7] Tebeu, P.M., Gregory, H.E., Itambi, D.M., Enow, M.R., Mawamba, Y. and Fomulu, J.N. (2015) Maternal Mortality in Cameroon: A University Teaching Hospital Report. PAMJ, 21, Article number: 16. https://doi.org/10.11604/pamj.2015.21.16.3912

[8] Filippi, V., Ronsmans, C., Campbell, O., Graham, W.J., Mills, A. and Borghi, J. (2006) Maternal Health in Poor Countries: The Broader Context and a Call for Action. The Lancet, 368, 1535-1541. https://doi.org/10.1016/S0140-6736(06)69384-7

[9] GBD (Global Burden of Disease) (2013) Mortality and Causes of Death, Collaborators. Global, Regional, and National Age-Sex Specific All-Cause and Cause-Specific Mortality for 240 Causes of Death, 1990-2013: A Systematic Analysis for the Global Burden of Disease Study 2013. The Lancet, 385, 117-171. https://doi.org/10.1016/S0140-6736(14)61682-2

[10] Lorretta, F. and Ntoimo, F. (2007) Maternal Mortality in a Rural Referral Hospital in the Niger Delta, Nigeria. Journal of Obstetrics and Gynaecology, 27, 275-278. https://doi.org/10.1080/01443610701213687

[11] Cousens, S., Blencowe, H., Stanton, C., Chou, D., Ahmed, S., Steinhardt, L., Cre- 
anga, A.A., Tunçalp, O., Balsara, Z.P., Gupta, S., Say, L. and Lawn, J.E. (2011) National, Regional, and Worldwide Estimates of Stillbirth Rates in 2009 with Trends Since 1995: A Systematic Analysis. The Lancet, 377, 1319-1330.

https://doi.org/10.1016/S0140-6736(10)62310-0

[12] Singh, K., Moran, A., Story, W., Balley, P. and Chavane, L. (2014) Malaria as Major Causes Say L. Global Causes of Maternal Death: A WHO Systematic Analysis.

[13] Njotang, P., Ako, S. and Tebeu, P.M. (2008) Hypertension in Pregnancy Cameroon. Proceedings of the 2nd France-Cameroon Hypertension in Pregnancy Congress, Cameroon, 2004-2007.

[14] Mutihirand, J.T. and Vaderjagt, D.J. (2002) Regional, and National Age-Sex Specific All-Cause and Cause-Specific Mortality.

\section{Abbreviations}

UNICEF: United Nation Children Fund

HIV: Human Immunodeficiency Virus

AIDS: Acquired Immunodeficiency Virus

UNFPA: United Nation Population Fund

SDG: Sustainable Development Goal

WHO: World Health Organisation

SWR: South West Region

MMR: Maternal Mortality Rate 